University of Louisville

ThinkIR: The University of Louisville's Institutional Repository

$12-2012$

\title{
Examining effects of picture content on false recognition in consistent and inconsistent handers.
}

\author{
Rosanna G. Scott \\ University of Louisville
}

Follow this and additional works at: https://ir.library.louisville.edu/honors

Part of the Psychology Commons

\section{Recommended Citation}

Scott, Rosanna G., "Examining effects of picture content on false recognition in consistent and inconsistent handers." (2012). College of Arts \& Sciences Senior Honors Theses. Paper 3.

http://doi.org/10.18297/honors/3

This Senior Honors Thesis is brought to you for free and open access by the College of Arts \& Sciences at ThinkIR: The University of Louisville's Institutional Repository. It has been accepted for inclusion in College of Arts \& Sciences Senior Honors Theses by an authorized administrator of ThinkIR: The University of Louisville's Institutional Repository. This title appears here courtesy of the author, who has retained all other copyrights. For more information, please contact thinkir@louisville.edu. 
Examining Effects of Picture Content on False Recognition in Consistent and Inconsistent

Handers

By

Rosanna G. Scott

Submitted in partial fulfillment of the requirements for Graduation summa cum laude and for Graduation with Honors from the Department of Psychology

University of Louisville

Dec 2012 


\begin{abstract}
Multiple previous studies agree that inconsistent handers exhibit a memory advantage over consistent handers, oftentimes in reference to inconsistents exhibiting lower false alarm rates. Two recent studies have found contrasting data, demonstrating that, compared to consistently handed individuals, inconsistently handed individuals exhibit a higher false alarm rate in recognition memory following the encoding of pictures of objects, regardless of whether lures are pictures or object names. From this research, it is unclear whether inconsistent individuals have difficulty remembering pictures of all types, or only pictures of objects. In the current study, participants studied pictures without focal objects (i.e., landscapes and fractals), then were tested on their recognition memory for those pictures. Inconsistent handers exhibited higher hit rates and lower false alarm rates for fractals when compared to consistent handers, while inconsistent handers also demonstrated higher corrected recognition, regardless of picture type, in comparison to consistent handers. These findings suggest that inconsistent handers display an advantage in the recognition of abstract images, while previous research has suggested inconsistent handers have a disadvantage in relation to object items.
\end{abstract}

Keywords: handedness, picture recognition, abstract images, memory 
Examining Effects of Picture Content on False Recognition in Consistent and Inconsistent Handers

Personal handedness refers to an individuals' use of one hand or the other. More specifically, individuals may be classified as either consistently handed, if they dominantly use one hand (regardless of whether that hand is the right or the left), or inconsistently handed, if they exhibit a more generalized use of both hands. Research has shown that consistency of handedness, regardless of direction, serves as an important individual difference factor in memory (Lyle, Hanover-Torrez, Hacklander, \& Edlin, 2011). Specifically, inconsistent handers have repeatedly been found to display better episodic memory, which is memory involving the recollection of specific events (Propper \& Christman, 2004; Propper, Christman, \& Phaneuf, 2005), in comparison to consistent handers. Oftentimes the nature of the inconsistent memory advantage has been less false recall or false recognition, as was demonstrated with word pairs, where inconsistents were less likely to falsely label a rearranged word pair as one they had seen before (Lyle et al., 2012); with word lists, where inconsistents were less likely to recall words not included on the list they studied (Christman, Propper, \& Dion, 2004); and with false memories, where inconsistents were less likely to claim that misinformation was true (Lyle \& Jacobs, 2010). The inconsistent handed memory advantage has been shown with a multitude of stimuli, including faces, where inconsistents were less likely to identify briefly-flashed novel faces as famous faces (Lyle \& Osborn, 2011); autobiographical memories, where inconsistents demonstrated greater levels of autobiographical recollection (Parker \& Dagnall, 2010); and words, where inconsistents displayed superior word recall (Propper et al., 2005). Episodic memory is thought to involve the integration of information between the two hemispheres of the brain. Lyle, McCabe, and Roediger (2008) explained the relationship between handedness and 
memory as being driven by a third variable: interhemispheric interaction, which is "the transmission of neural signals between the left and right cerebral hemispheres via the corpus callosum and other forebrain commissures” (p. 523). Research by Cowell, Kertesz and Denenburg (1993) has suggested that inconsistently handed individuals have a different morphology of the corpus callosum compared to consistent handers, which may increase interaction between the two hemispheres in inconsistents. Furthermore, Christman and colleagues (2004) suggested that increased interhemispheric interaction (possibly due to a larger corpus callosum) may be associated with an enhanced ability to accurately monitor an item's source, or, in other words, to determine where a memory came from, thereby avoiding false memories. Zaidel and Sperry (1974) demonstrated that individuals with intact interhemispheric commissures exhibit superior retrieval compared to split-brain patients.

While previous research has repeatedly shown that inconsistently handed individuals have memory advantages across multiple test types and with various stimuli, two unpublished studies by Lyle have suggested that, in some situations, consistently handed individuals may have a memory advantage: consistent handers have been found to have fewer false memories compared to inconsistent handers after studying pictures of objects. The procedures in these two studies were different—in one study, pictures of objects were studied, but participants were tested on names of objects (i.e., did you see a picture of a boat?), while in the other study pictures of objects were studied and pictures were tested (i.e., did you see this picture?). In these studies, when names and pictures of objects that had not been studied were tested, consistent participants were less likely than inconsistent participants to say they had studied pictures of the objects (i.e., they had a lower false alarm rate). From these prior studies, it is not clear whether 
inconsistent handers have difficulty remembering pictures of objects per se, or whether all pictures, regardless of content, would be poorly remembered by these individuals.

The current study posits several questions derived from prior research, most importantly the recent studies suggesting the inconsistent hander's memory disadvantage. Is the difference in false alarm rate between consistents and inconsistents a result of the content of the picture or is it the fact that the item is a picture that affects false recognition? If prior research suggests that inconsistents falsely recognize pictures of objects more than consistents do, would pictures of images with no focal point or of abstract content produce different results?

\section{Method}

\section{Participants}

Participants were 72 University of Louisville students enrolled in psychology courses (54 female, 18 male) who were recruited using the SONA research participation system and ranged in age from 18 to 30 years ( $M=21.1$ years). Participants received course credit for participating. Forty-eight participants were classified as consistent handers, the other 24 participants were classified as inconsistent handers (the process of classification will be explained in Materials and Procedures).

\section{Materials and Procedures}

Participants first read and signed the consent form. Participants then completed a modified version of the Edinburgh Handedness Inventory (Oldfield, 1971), which assessed whether the participants were consistently or inconsistently handed. The handedness inventory asked participants to indicate, on a scale from “Always Left” to "Always Right”, which hand 
they use for 10 everyday activities (e.g., combing one's hair or using a spoon). When scoring the inventory, each “Always Left” response is worth -10 points, each “Usually Left” response is worth -5 points, each “No Preference” response is worth 0 points, each "Usually Right” response is worth 5 points, and each “Always Right” response is worth 10 points. The participant's handedness score was based on the point total from all 10 responses. If the score was greater than or equal to +80 or less than or equal to -80 , then the participant was classified as consistently handed. If the score was between +80 and -80 , then the participant was classified as inconsistently handed. After participants’ handedness classification was determined they read instructions for the computer program then viewed a sequence of 23 landscape pictures and 23 fractal pictures. The picture types were chosen by the nature of their content-landscapes because of their lack of focal object (see Figure 1 for an example), and fractals because of their abstract imagery. Fractals are computer-generated images that are derived from geometric equations (see Figure 2 for an example). Pictures were taken from two online sources: an online fractal archive and a website with archives of landscapes and other images of nature (stimuli are available from the author upon request). Pictures were shown on a computer screen one at a time for two seconds. The first and last three images were inserted as primacy and recency buffers and were not included in the data analysis. After these 46 pictures were shown, participants viewed a second sequence of pictures consisting of 43 landscape pictures and 43 fractal pictures, for a total of 86 pictures. Half of the 86 pictures participants had seen in the first sequence while the other half were new. Pictures were shown on a computer screen one at a time. Participants pressed the " $z$ " key on a computer keyboard if the picture was one that had been seen in the first sequence or the "m" key if the picture was one that had not been seen in the first sequence. This test was self-paced. In both the study and test phases, pictures were presented randomly. After 
the second sequence of pictures was complete the participant was debriefed via the last slide of the computer program.

\section{Data Analysis}

The experiment had a 2 (handedness: inconsistently handed or consistently handed) X 2 (picture type: fractal or landscape) mixed design with the first factor being between-subjects and the second factor being within-subjects. The data were submitted to a $2 \mathrm{X} 2$ factorial ANOVA and the dependent variables were hit rate (when the participant correctly identified a test picture as one that had been seen in the previous sequence), false alarm rate (when the participant falsely identified a novel picture as one that had been seen in the previous sequence), and corrected recognition (i.e., hit rate minus false alarm rate).

\section{Results}

\section{Hit Rate}

There was a main effect of picture type on hit rate, $F(1,70)=5.498, p=.022$. There was a higher hit rate for fractals $(M=.75)$ than for landscapes $(M=.72)$, regardless of handedness. No significant main effect of handedness on hit rate was found. The interaction between handedness and the hit rate of landscapes was not significant.

\section{False Alarm Rate}

There was a main effect of picture type on false alarm rate, $F(1,70)=48.61, p<.001$, with a higher false alarm rate for fractals $(M=.24)$ than for landscapes $(M=.09)$. There was also a main effect of handedness on false alarm rate, $F(1,70)=7.438, p=.008$, with a higher false alarm rate for consistents $(M=.19)$ than for inconsistents $(M=.13)$. These main effects 
were qualified by an interaction that approached significance, $F(1,70)=3.818, p=.055$. There was little difference in false alarm rates of landscapes between consistents $(M=.08)$ and inconsistents $(M=.1)$. Consistents and inconsistents responded differently to novel fractal pictures, as inconsistents were less likely to false alarm to fractals than were consistents, while both groups responded similarly to novel landscape pictures.

\section{Corrected Recognition}

Corrected recognition is a measure that combines the hit rate and false alarm rate (the participants' false alarm rate subtracted from their hit rate). There was a main effect of handedness on corrected recognition, $F(1,70)=5.795, p=.019$, where inconsistent handers displayed higher levels of corrected recognition $(M=.61)$ than consistent handers $(M=.52)$. There was also a main effect of picture type on corrected recognition, $F(1,70)=17.299, p<.001$, with higher corrected recognition for landscapes $(M=.62)$ than for fractals $(M=.52)$. These main effects were qualified by a significant interaction between picture type and handedness, $F(1,70)=8.036, p=.006$. Inconsistents and consistents responded differently to fractal pictures, as inconsistents demonstrated higher levels of corrected recognition for fractals $(M=.6)$ compared to consistent handers $(M=.44)$, while both groups responded similarly to landscape pictures ( $M s=.63$ and .61 for inconsistent handers and consistent handers, respectively). A twosample $t$ test was run to determine whether the difference in corrected recognition for fractals between consistent and inconsistent handers was significant. The difference was significant, $t(70)=3.572, p=.001$

\section{Discussion}


The current study was conducted to help better understand memory differences between consistent handers and inconsistent handers. In the past, multiple studies have suggested that inconsistent handers have an advantage, and as described in the Introduction, the nature of the inconsistent advantage has often been less false recall or recognition. In other words, inconsistents often seem to have an advantage in knowing what did not happen. However, two unpublished studies by Lyle suggested otherwise: that inconsistents have a higher false alarm rate compared to consistent handers after studying pictures of objects. These contradictory data are what prompted the current study, because they raise the question of whether inconsistent individuals have difficulty remembering all types of pictures, or only pictures of objects. The current study showed that inconsistents exhibited lower false recognition for at least one type of picture (i.e., fractals). Taken together, the lower false alarm rate for consistents in regard to pictures of objects and the lower false alarm rates for inconsistents in regard to abstract pictures indicates that the direction of handedness-based memory advantages depends on the content of the picture (objects versus abstract), and not on whether the to-be-remembered stimulus is a picture or not.

The lower false alarm rate shown by inconsistent handers in this study was only present for fractals; a difference was not seen between inconsistents and consistents with landscapes. This may reflect the fact that landscapes are less abstract than fractals; they are better described as having no focal point. Landscapes still include objects and can be labeled in a general way (e.g., "desert” or "forest”), which makes them, in some form, like a picture of an object. Because landscape pictures fall between completely abstract pictures like fractals and pictures consisting solely of focal objects, it may be sensible that the difference in false alarm rate between the two 
handedness groups for landscapes was not significant, while it was significant (favoring inconsistents) in fractals and also significant (favoring consistents) in object pictures.

Future research would be needed to determine exactly why inconsistent individuals have a higher false alarm rate after studying pictures of objects, despite having a lower false alarm rate in many other domains. However, there is something about the content of pictures being an object that leads to different memory performance between consistent handers and inconsistent handers. These two groups of people are defined by how they interact with objects (the EHI used to classify them is a questionnaire about how they use objects), and it may be that, when inconsistents think about objects, they have different brain activity compared to consistent handers, somehow changing their memory for objects.

The implications of this study (and previous similar studies) extend beyond recognition of different picture types. False alarm rates represent false memories, therefore consistent and inconsistent handers, in essence, have differential ability to know what did and did not happen in the past based on what it is that they are remembering. Overall, it seems that inconsistent handers have an advantage with a number of types of to-be-remembered information studied in the past, including highly abstract images, while consistents seem to display more accurate recognition of what was and was not seen in regards to objects.

In conclusion, inconsistent handers had a lower false alarm rate for fractals compared to consistent handers. In reference to the question posited in the Introduction, it seems that the memory disadvantage for inconsistent handers in recognizing object pictures stems from the content of the picture (an object image versus an abstract image), and the current study discredits the possibility that the disadvantage is due to the fact that what was studied was a picture. 


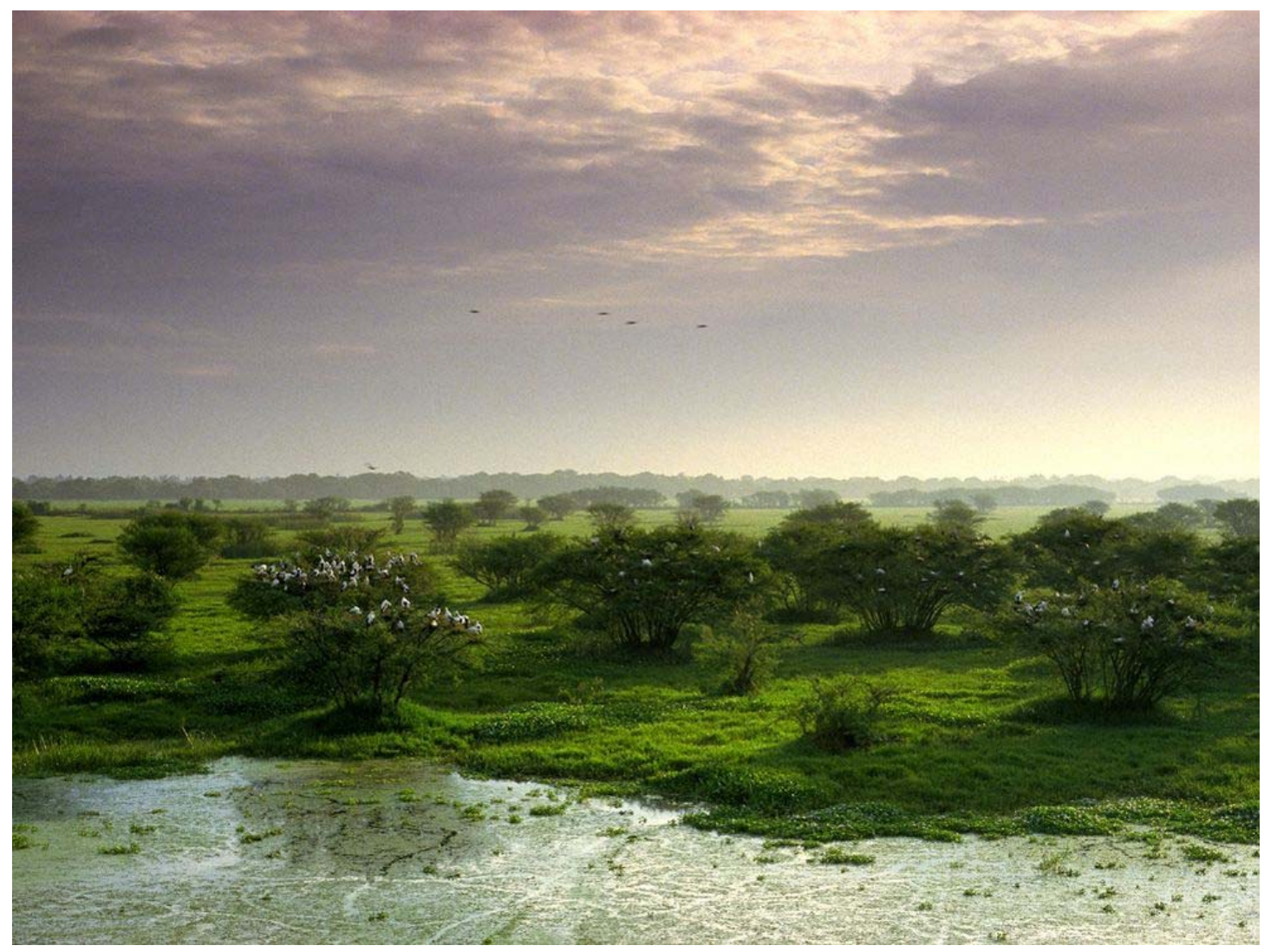

Figure 1. Example of a landscape picture. 


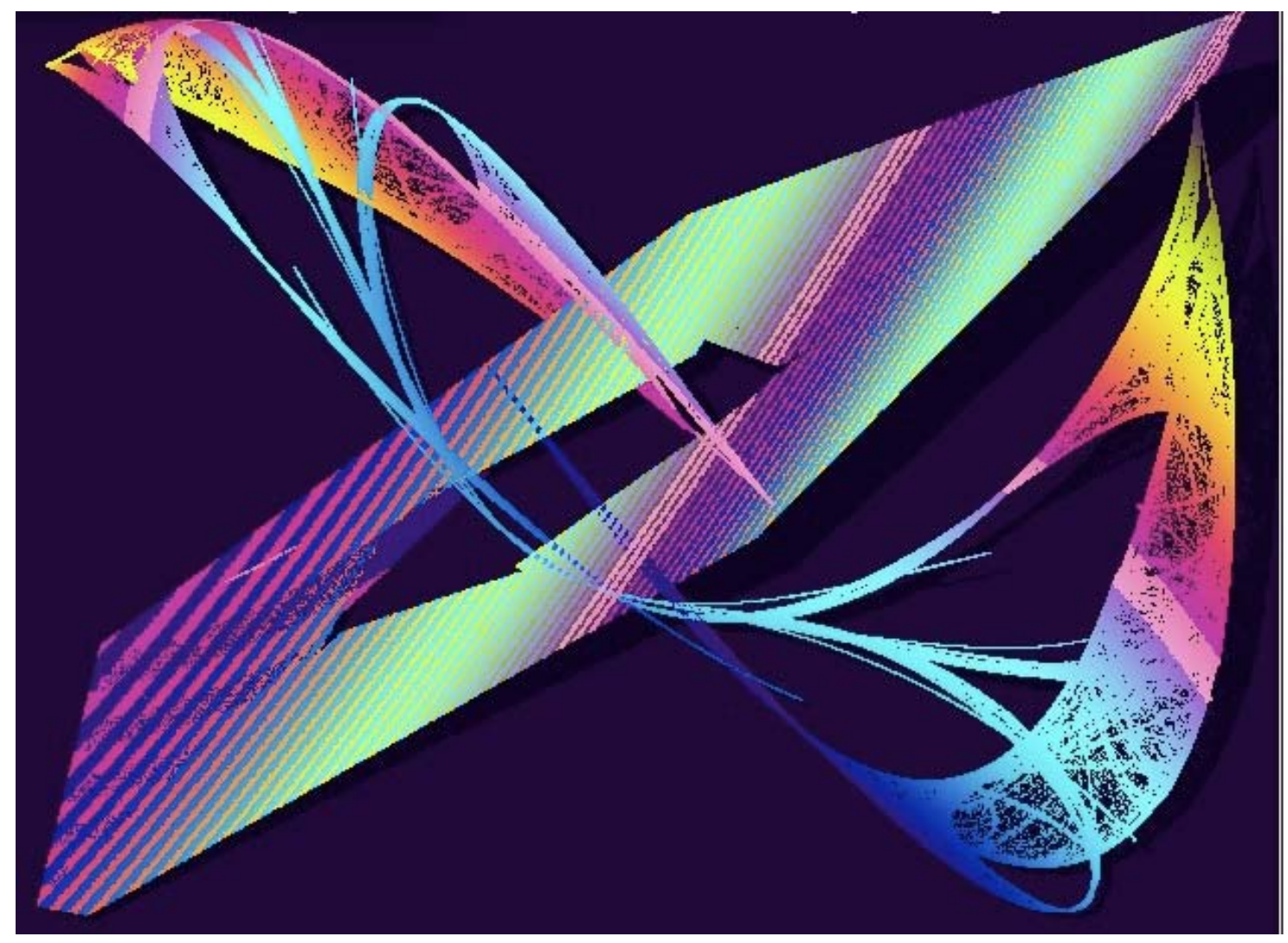

Figure 2. Example of a fractal picture. 


\section{References}

Christman, S._D., Propper, R._E., \& Dion, A. (2004). Increased interhemispheric interaction is associated with decreased false memories in a verbal converging semantic associates paradigm. Brain and Cognition, 56, 313-319.

Cowell, P._E.2 Kertesz, A. \& Denenburg, D._H. (1993). Multiple divisions of Handedness in the Corpus Callosum. Neurology, 43, 2353-2357

Lyle, K._B., Hanaver-Torrez, S._D., Hackländer, R._P., \& Edlin, J.M. (2012). Consistency of handedness, regardless of direction, predicts baseline memory accuracy and potential for memory enhancement. Journal of Experimental Psychology: Learning, Memory, and Cognition, 38, 187-193.

Lyle, K._B., \& Jacobs, N._E. (2010). Is saccade-induced retrieval enhancement a potential means of improving eyewitness evidence? Memory, 18, 581-594.

Lyle, K._B., McCabe, D._P., \& Roediger, H._L., III. (2008). Handedness is related to memory via hemispheric interaction: Evidence from paired associate recall and source memory tests. Neuropsychology, 22, 523-530.

Lyle, K._B., \& Orsborn, A._E. (2011). Inconsistent handedness and saccade execution benefit face memory without affect interhemispheric interaction. Memory, 19, 613-624.

Oldfield, R. (1971). The assessment and analysis of handedness: The Edinburgh Inventory. Neuropsychologia, 91, 152-162.

Parker, A., \& Dagnall, N. (2010). Effects of handedness and saccadic bilateral eye movements on components of autobiographical recollection. Brain and Cognition, 73, 93-101. 
Propper, R. E. \& Christman, S. (2004). Mixed- versus strong right-handedness is associated with biases toward 'remember' versus 'know' judgments in recognition memory: Role of interhemispheric interaction. Memory, 12, 707-714.

Propper, R._E., Christman, S._D., \& Phaneuf, K._A. (2005). A mixed-handed advantage in episodic memory: A possible role of interhemispheric interaction. Memory \& Cognition, 33, 751-757.

Zaidel, D., \& Sperry, R. W. (1974). Memory impairment after commissurotomy in man. Brain 97, 263-272. 